\title{
Dynamics of soil fertility and maize growth with lower environment impacts depending on a combination of organic and mineral fertilizer
}

\author{
Wenwen Zhang ${ }^{1,2,3}$,Chong Wang ${ }^{1,2,3^{*}}$, Mingming Dong ${ }^{1,2,3}$, Shujie Jin ${ }^{1,2,3}$, Huan Li $^{1,2,3}$
}

${ }^{1}$ Beijing Key Laboratory of Biodiversity and Organic Farming, College of Resources and Environmental Sciences, China Agricultural, Beijing, China ${ }^{2}$ Key Laboratory of Plant-Soil Interactions, MOE. Ministry of Education, Center for Resources, Environment and Food Security, China Agricultural University, Beijing,China. . ${ }^{3}$ College of Resources and Environmental Sciences, China Agricultural University, Beijing 100193, China. *Corresponding author:wangchong@cau.edu.cn

\begin{abstract}
:
The combined application of organic and mineral fertilizers is gaining recognition as a viable approach to address the decline of soil fertility in intensive cultivation. A four-year experiment was conducted to study the dynamics of maize growth and analyse environmental changes. Two treatments were designed, (I) mineral fertilizer treatments (MF) that received the optimal fertilization level with $185 \mathrm{~kg} \mathrm{~N} / \mathrm{ha}, 60 \mathrm{~kg} \mathrm{P}{ }_{2} \mathrm{O}_{5} / \mathrm{ha}$, and $90 \mathrm{~kg}$ $\mathrm{K}_{2} \mathrm{O} / \mathrm{ha}$ and $(\Pi)$ the combination of organic and mineral fertilizer treatments (OMF) with the application of 3.75 $\mathrm{t} /$ ha organic fertilizer supplemented with $125 \mathrm{~kg} \mathrm{~N} \mathrm{ha}^{-1}$. The results indicated that OMF could improve the maize yield by 9.7-13.6\%, while the aggregate environmental index was reduced by $17 \%$ compared with MF. Principal component analysis (PCA) showed that OMF promotes maize growth and yield attributed to the increased $\mathrm{N}, \mathrm{P}$ and $\mathrm{K}$ uptake at the 12-leaf stage and tasseling stage, and the increased urease activity and $\mathrm{P}$ uptakes at the harvest stage. Life cycle assessment (LCA) analysis indicated that OMF decreased energy consumption, greenhouse gas emissions, acidification and aquatic eutrophication compared with MF. The results clearly revealed that organic applied with less mineral fertilizer had a higher maize yield and lower agricultural environmental risk compared to only mineral fertilizer.
\end{abstract}

Keywords: life cycle assessment, plant biomass, soil enzyme activities, soil nutrients, maize yield stability, organic and mineral fertilizer. 


\section{Introduction}

As the world population and agricultural resource limitation are increasing, global food security has become an acute problem. Increased agricultural production has mainly depended on the use of new crop varieties, pesticides and mineral fertilizers in China over the last 50 years (Xie et al., 2011). Excessive chemical fertilization has led to soil quality degradation and the deterioration of the agricultural environment. In the future, effective and practical approaches must be taken to address the unprecedented challenges and achieve both high crop productivity and high resource use efficiency in intensive agriculture (Shen et al., 2013).

In 2015, the Chinese Ministry of Agriculture launched a campaign on zero growth of chemical fertilizer consumption by 2020 , which depends on promoting accurate fertilization, adjusting the fertilizer consumption structure and using more organic fertilizer to replace chemical fertilizers. Organic fertilizer elevates nitrogen and phosphate availability as well as assists in plant residue decomposition, which improve the soil health and quality, reduce soil water loss, and suppress pathogens (Scotti et al. 2015). The ability of organic sources to meet the crop nutrient requirements is not as assured as that of mineral fertilizers, while the combination of organic and mineral fertilizers has many advantages, such as increasing productivity, reducing chemical fertilizer consumption and protecting the environment (Moreno-Cornejo et al. 2017; Yang et al., 2015). The positive effects of the interactions between organic and mineral fertilizers on crop yield might be due to the temporary immobilization of $\mathrm{N}$ by organic fertilizers, improving the synchrony between nutrient supply and demand (Palm et al., 2001). On the other hand, nutrient cycling and the associated yield benefits derived from combining organic and mineral fertilizers depend on many factors, including the climate, soil bio-physical-chemical environment, organic fertilizer quality and interactions among these factors (Sanchez et al., 2016). However, all of the above studies focused on soil nutrients and their transport throughout the planting year, but the dynamics of soil nutrients and their use in the key stages of maize growth have not been well studied. Crops have different nutrient demands at different growth stages, and fertilization based on the temporal dynamic of nutrient uptake may ensure that the supply does not exceed the rate of nutrient demand (Ma et al., 2013). Therefore, research that matches the dynamics of soil nutrient supply and nutrient uptake by crops as a function of organic and mineral fertilizer combinations in long-term experiments is greatly needed.

The challenge of agriculture sustainability requires solving the trade-off between producing satisfactory levels of agricultural products, both in terms of quantity and quality, and reducing the environmental impacts. Some information has shown that the replacement of mineral fertilizers with organic fertilizers can decrease greenhouse gas emissions (Mapanda et al., 2011), while others demonstrated that greenhouse gas emissions in treatments with organic and mineral fertilizers were higher than in treatments with only mineral fertilizer (Carmo et al., 2013). However, there is little information on how the combination of organic and mineral fertilizers impacts the potential for acidification and aquatic eutrophication in the cropping system. LCA analysis is an approach for assessing the environmental impacts associated with a product, process or activity by identifying and quantifying all resources consumed as well as emissions and wastes released (Brodt et al., 2014). All impacts are related to a common unit and are aggregated into a comprehensive environmental 
index. This index allows different products or production to be ranked alternatives according to their overall environmental performance. Although LCA has been more widely applied in agricultural than in industrial fields, few reports are available on its use for analyzing agricultural products (i.e., wheat, sugar beet and maize) and cropping systems' impacts on the environment (Nie et al., 2010).

The main purpose of this study was to (i) explore whether the combined application of mineral and organic fertilizers can obtain the same high and stable maize yield as the application of optimal mineral fertilizers at equivalent macronutrient levels; (ii) study the effects of OMF on the relationship of the crop demand and soil supply of nutrients in key growth stages; and (iii) access the agricultural environmental impact of both the MF system and OMF system to see whether the combined application of mineral and organic fertilizers reduces environmental risks. This research will provide a reference for minimum mineral fertilizer use and sustainable agriculture development. LCA was used to assess the environmental impact of summer maize production with the combined application of organic and mineral fertilizers. The analysis includes raw material extraction and transportation, agrochemical production and transportation and arable farming in the field (Wang, 2014).

\section{Material and Methods}

\subsection{Experimental site and design}

The experiment was conducted for four years during the maize planting seasons of 2010, 2011, 2012 and 2013 at the Quzhou experimental station of China Agricultural University $\left(36^{\circ} 34^{\prime}-36^{\circ} 57^{\prime} \mathrm{N}, 114^{\circ} 50^{\prime}\right.$ $\left.115^{\circ} 13^{\prime} \mathrm{E}\right)$. The average annual temperature is $13.6^{\circ} \mathrm{C}$, annual precipitation is $477.6 \mathrm{~mm}$, and average frost- free period is $201 \mathrm{~d}$ (1981-2010, http://data.cma.cn/ site/index.html). The loamy sand soil at the experimental site had $6.61 \mathrm{~g}$ of organic $\mathrm{C} \mathrm{kg}^{-1}, 1.3 \mathrm{~g}$ of total $\mathrm{N} \mathrm{kg}^{-1}, 6.80 \mathrm{mg}$ of available $\mathrm{P}$ (Olsen-P) kg $\mathrm{kg}^{-1}, 30.2 \mathrm{mg}$ of exchangeable $\mathrm{K}\left(\mathrm{NH}_{4} \mathrm{OAc}-\mathrm{K}\right) \mathrm{kg}^{-1}$, and a $\mathrm{pH}\left(\mathrm{H}_{2} \mathrm{O}\right.$, soil 2.5:1, v/v) of 8.86 .

In Quzhou County, major soils used for crop production are calcareous. The arable land in the area is dominated by winter wheat (Triticum spp.)/summer maize (Zea mays L.) production systems. Two treatments were designed in the field experiments, (I) MF plots that received the optimal fertilization level with $185 \mathrm{~kg} \mathrm{~N} \mathrm{ha}^{-1}$ as urea in split applications $(13.5 \%$ at sowing, $69.2 \%$ in the six-leaf stage, and $17.3 \%$ in the twelve-leaf stage), $60 \mathrm{~kg} \mathrm{P}_{2} \mathrm{O}_{5}$ ha $^{-1}$ as superphosphate at sowing, and $90 \mathrm{~kg} \mathrm{~K}_{2} \mathrm{O} \mathrm{ha}^{-1}$ as potassium sulphate in split applications (50\% at sowing and $50 \%$ in the sixleaf stage) and (П) OMF plots that received $3.75 \mathrm{tha}^{-1}$ organic fertilizer (made from fermented livestock and poultry manure, cottonseed meal and chaff bran with $1.6 \% \mathrm{~N}, 1.7 \% \mathrm{P}, 2.5 \% \mathrm{~K}$, and $41 \%$ organic matter, and bought from Yantai Zhongde agric. sci. tech. co.) supplemented with $125 \mathrm{~kg} \mathrm{~N}^{-1}$ at sowing. The soil total $\mathrm{N}$, available $\mathrm{P}$ and exchangeable $\mathrm{K}$ were equivalent in the MF and OMF treatments, as determined by the methods described in the sampling and analysis section. There were four replicates of each treatment plot (5 m × $12 \mathrm{~m}$ ). Summer maize (Zheng Dan 958, a local conventional variety grain maize) was planted at a density of 48000 seedings per ha. Sowing was manually performed sometime between the $10^{\text {th }}$ and $20^{\text {th }}$ of June in 2010-2013 after a good rain to provide moisture for good germination. Mineral and organic fertilizers used as basal fertilizer were evenly broadcast onto the soil surface by hand and immediately incorporated into the plowed soil ( $0-20 \mathrm{~cm}$ depth) by tillage before sowing of wheat and maize, and tillage was performed to a $20 \mathrm{~cm}$ depth by a shovel, followed by a rake. 
Additionally, supplementary fertilizer was applied as described above in the treatment design. Each treatment was irrigated $120 \mathrm{~mm}$ immediately after sowing. All treatments were irrigated twice to keep a 60-80\% field capacity during the dry seasons in 2010 (on 27 June and 20 July) and 2012 (on 23 June and 25 July). The mix $(1: 1 \mathrm{v} / \mathrm{v})$ of atrazine $(25 \%)$ and acetochlor $(25$ $\%)$ was applied at $1.56 \mathrm{~kg} \mathrm{ha}^{-1}$ as pre-emergent herbicides. The mix $(1: 1 \mathrm{v} / \mathrm{v})$ of imidacloprid $(25 \%)$ and fipronil (19\%) was applied at $400 \mathrm{ml}$ per $100 \mathrm{~kg}$ seed as seed-coating pesticides. All plots were continuously used under winter wheat-summer maize rotation since the start of the experiment, and crop residue was returned to the soil after harvest every year.

\subsection{Sampling and analysis}

Shoot, root and soil samples were collected at four different growth periods, i.e., the six-leaf stage (6S), 35 days from seeding, when approximately $50 \%$ of the population internode had begun to elongate), twelve-leaf stage (12S), 53 days from seeding, heart leaves growing in clusters, the upper leaves resembling a large bell, tasseling stage (TS), 66 days from seeding, approximately $50 \%$ of the $3-5 \mathrm{~cm}$ tassel had emerged and harvest stage (HS), 118 days from seeding. Immediately after plant harvest, soil cores were taken for soil analysis and root measurement. A tube type soil auger with a diameter of $0.05 \mathrm{~m}$ was used to collect three undisturbed core soil samples per sampling profile down to a depth of $0.2 \mathrm{~m}$. The three auger profiles were taken between two rows at a distance of $1.5 \mathrm{~m}$ from the plot edges. The three samples were mixed and sieved $(2 \mathrm{~mm})$ to obtain one sample per plot. Roots were collected by handpicking and then washed, dried $\left(65^{\circ} \mathrm{C}, 48 \mathrm{~h}\right)$ and weighed. Each shoot, corresponding to the collected root, was sampled as close as possible to the ground.
Maize shoots were dried $\left(65^{\circ} \mathrm{C}, 48 \mathrm{~h}\right)$ and weighed. Mazie grain was manually harvest as a sub-sample with a $5 \mathrm{~m}$ length and 4-row width, and the distance between two adjacent lines was $60 \mathrm{~cm}$.

Soil organic C (SOC) was determined by the $\mathrm{K}_{2} \mathrm{Cr}_{2} \mathrm{O}_{7}$ colorimetric oxidization method (Shitan, 2000). Soil total $\mathrm{N}$ was measured by the Kjeldahl method (Bremner, 1960). Soil available P was determined by $\mathrm{NaHCO}_{3}$ extraction $\left(0.5 \mathrm{~mol} \mathrm{~L}^{-1}\right)$ and spectrophotometrically measured at $880 \mathrm{~nm}$ using the phosphomolybdate method (Murphy and Riley, 1962). Soil exchangeable K was determined by the $\mathrm{NH}_{4} \mathrm{OAC}$ extraction $\left(1 \mathrm{~mol} \mathrm{~L}^{-1}\right)$-flame photometric method (Shitan, 2000). Samples of oven-dried roots and shoots were analysed for total $\mathrm{N}$ concentrations using Kjeldahl oxidation (Axmann et al., 1990). Total $\mathrm{P}$ concentration was colorimetrically determined at $440 \mathrm{~nm}$ using the molybdate procedure on $2 \mathrm{~g}$ of pulverized samples (Murphy and Riley, 1962) and total $\mathrm{K}$ was determined by flame photometry after steaming in $\mathrm{H}_{2} \mathrm{SO}_{4}-\mathrm{H}_{2} \mathrm{O}_{2}$ (Shitan, 2000). The urease and alkaline phosphatase activities were determined according to the procedure of Li et al. (2013).

\subsection{Life cycle assessment methodology (LCA)}

The LCA of this experiment (2010-2013) was performed according to the International Organization for Standardization (ISO 14040) and the Society for Environmental Toxicology and Chemistry (SETAC) (ISO, 1998). The system boundaries of this LCA were from a mineral and fossil fuel cradle to maize grain harvest (Xue et al., 2012), and there was an appropriate functional unit of one ton of grain. The assessment covered the period starting with the harvest of the crop preceding the beginning of the experiment in summer 2010 and ending with the harvest of the last crop in 2014. Inventory analysis compiled all 
emissions that were released by fertilization in the specific system under investigation and related them to the defined functional unit (ISO, 1998). Emissions, including $\mathrm{NOx}, \mathrm{CH}_{4}$ and $\mathrm{CO}_{2}$, due to energy consumption in the agriculture material production and heavy metal emissions were calculated using SimaPro 7.1 (Liang et al., 2009). The study considered a range of potential impacts, namely, the demand for non-renewable energy resources (e.g., fossil energy consumed during fertilizer production), the contribution to greenhouse gas emission, acidification, eutrophication and the impact on terrestrial ecotoxicity were analysed (Nemecek et al., 2008). Assessment classification was performed to understand the relevant differences between MF and its equivalent replacement by $\mathrm{OMF}$, which is a promising option for dealing with the challenges in global resource management, environment protection and food security.

\subsection{Data analysis}

The temporal stability (S) for each fertilization treatment was calculated as $S=\mu / \delta$, where $\mu$ is the mean yield value for a time period and $\delta$ is its temporal SD (standard deviation) over the same time interval (Xie et al., 2011). Soil nutrients, plant growth, quantity and temporal stability of maize yield were compared in the MF vs. OMF treatments with repeated measures ANOVA. Two-way ANOVAs in the GLM were used to analyze the fertilization treatment or growing season on soil nutrients and plant growth of each year. The HSD Tukey test was performed to analyze the effects of the different growth stages on soil nutrients and plant growth over four years. Before analysis, data were log-transformed to meet assumptions of normality and homogeneity of variance. All of the above statistical analyses were performed with SPSS17.0. The average value of soil and plant parameters for each treatment over the four years was subjected to the principal component analysis (PCA) data using the Canoco version 4.5 software package. PCA allows for identification of the components responsible for the total variation of the data as well as the variable groups that explain these variations.

\section{Results}

\subsection{Maize yields and temporal stability of yields}

Compared with MF treatment, OMF treatment significantly improved the maize yield by $13.6 \%, 9.7 \%$ and $10.8 \%$ in 2010, 2011 and 2013, respectively ( $P$ $<0.05$, Figure 1). The maize yield was higher with OMF than with MF in 2012, although the effect was not statistically significant. The field experiment results showed that the maize yield ( $\mathrm{F}=11.621, P=$ 0.014 ) was higher in the OMF treatments than in the MF treatments over the four years. The temporal stability of the maize yield $(\mathrm{F}=0.070, P=0.556)$ did not differ between MF and OMF over the four experimental years (Figure 1). This result indicated that the combination of mineral and organic fertilizers can provide equal temporal stability for the summer maize yield compared with the optimal mineral fertilizers. 


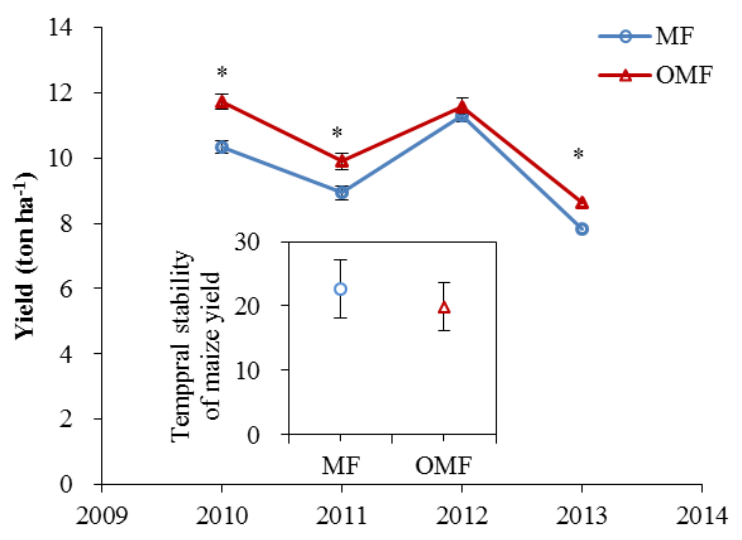

Figure 1. Maize yield and temporal stability in MF and OMF systems over the four years $(2010 \sim 2013)$. The mean values \pm SE are shown ( $\mathrm{n}=4)$. ' ${ }^{*}$ ' indicates that maize yield has a significant difference between $\mathrm{OMF}$ and $\mathrm{MF}$ at $P<0.05$.

\subsection{Dynamics of soil nutrients}

The results showed that the SOC $(\mathrm{F}=39.878, P$ $<0.001)$, soil total $\mathrm{N}(\mathrm{F}=41.679, P<0.001)$, soil available $\mathrm{P}(\mathrm{F}=817.265, P<0.001)$, soil exchangeable $\mathrm{K}(\mathrm{F}=582.077, P<0.001)$, urease $(\mathrm{F}$ $=17.066, P<0.001)$ and alkaline phosphatase $(\mathrm{F}=$ $6.465, P=0.017)$ activity were higher in the $\mathrm{OMF}$ treatments than in the MF treatments over the four years (Figure 2). Compared with MF, OMF increased the SOC by $14 \%, 16 \%$ and $12 \%$ in the $6 \mathrm{~S}, 12 \mathrm{~S}$ and $\mathrm{HS}$ over the four years, respectively $(P<0.05)$. There were no significant differences in the SOC content among the four growing seasons (Figure 3). Compared with MF, the soil total $\mathrm{N}$ with OMF was increased by $17 \%(P<0.01), 22$ $\%(P<0.01), 16 \%(P<0.05)$ and $24 \%(P<0.01)$ in the $6 \mathrm{~S}, 12 \mathrm{~S}$, TS and HS over three years $(2010$,
2012 and 2013), respectively. The soil total N during the four growing seasons did not significantly vary (Figure 3 ). The soil available $\mathrm{P}$ were higher in the OMF treatments than in the MF treatments in the $6 \mathrm{~S}$ (2.7 times), 12S (3.4 times), TS (3.0 times) and HS $(4.3$ times) over four years $(P<0.001)$. The soil available $\mathrm{P}$ with $\mathrm{OMF}$ was significantly higher in the $12 \mathrm{~S}$ than in the TS and HS $(P<0.05)$. In the MF treatments, the soil available $\mathrm{P}$ content of the TS and HS was significantly lower than that of the $6 \mathrm{~S}(P<0.05$, Figure 3$)$. Compared with MF, OMF increased the soil exchangeable $\mathrm{K}$ by $84 \%$, $98 \%, 100 \%$ and $130 \%$ in the $6 \mathrm{~S}, 12 \mathrm{~S}$, TS and HS over the four years, respectively $(P<0.001$, Figure $3)$. The soil exchangeable $\mathrm{K}$ with the MF treatment was lower in the HS than in the $12 \mathrm{~S}(P<0.05)$. The soil exchangeable $\mathrm{K}$ with the OMF treatment was higher in the HS than in the $6 \mathrm{~S}(P<0.05)$. 

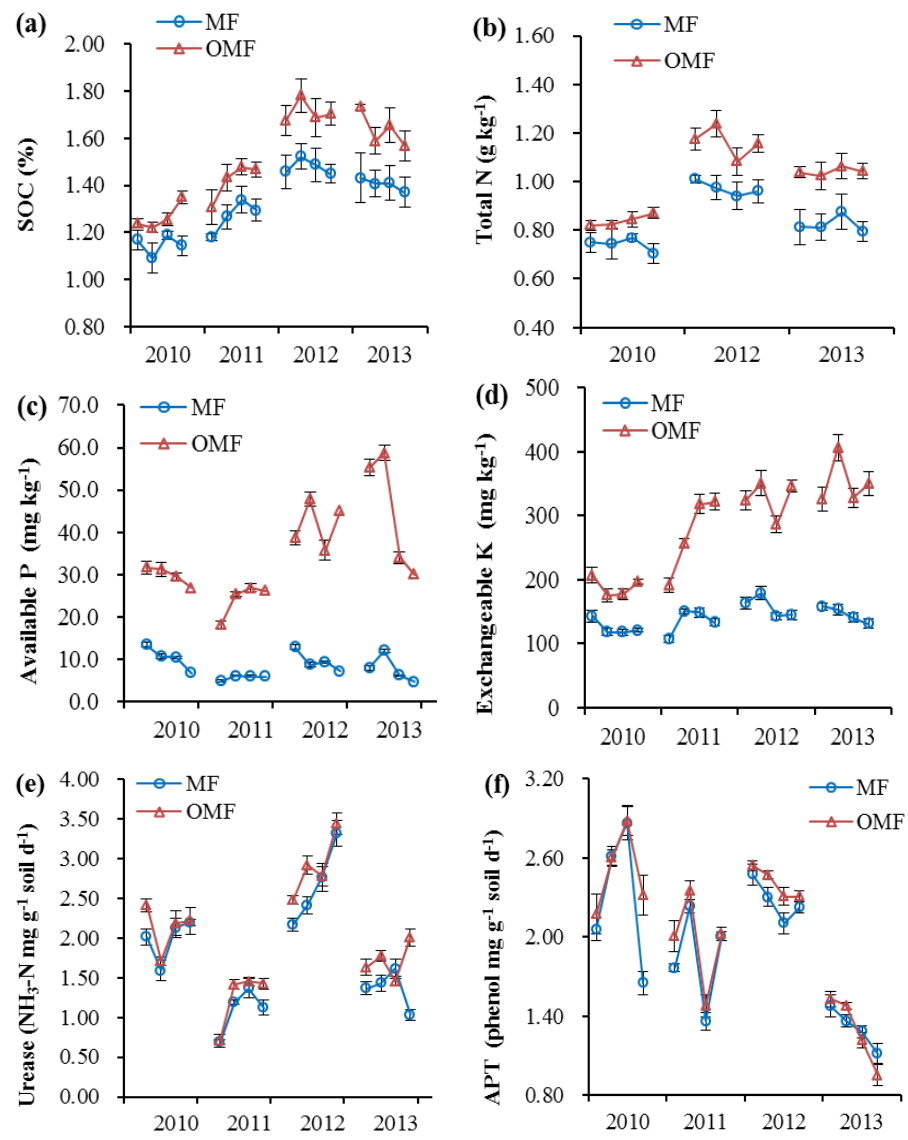

Figure 2. Soil organic carbon (SOC), total N, available $\mathrm{P}$, exchangeable $\mathrm{K}$, urease and alkaline phosphomonoesterase activity (APT) in the mineral fertilizer treatments (MF) and the treatments with organic fertilizer combined with smaller amounts of mineral fertilizer (OMF). Data are the mean values $\pm \mathrm{SE}(\mathrm{n}=4)$. No detection of the total $\mathrm{N}$ in 2011, so the relevant data is not listed. 

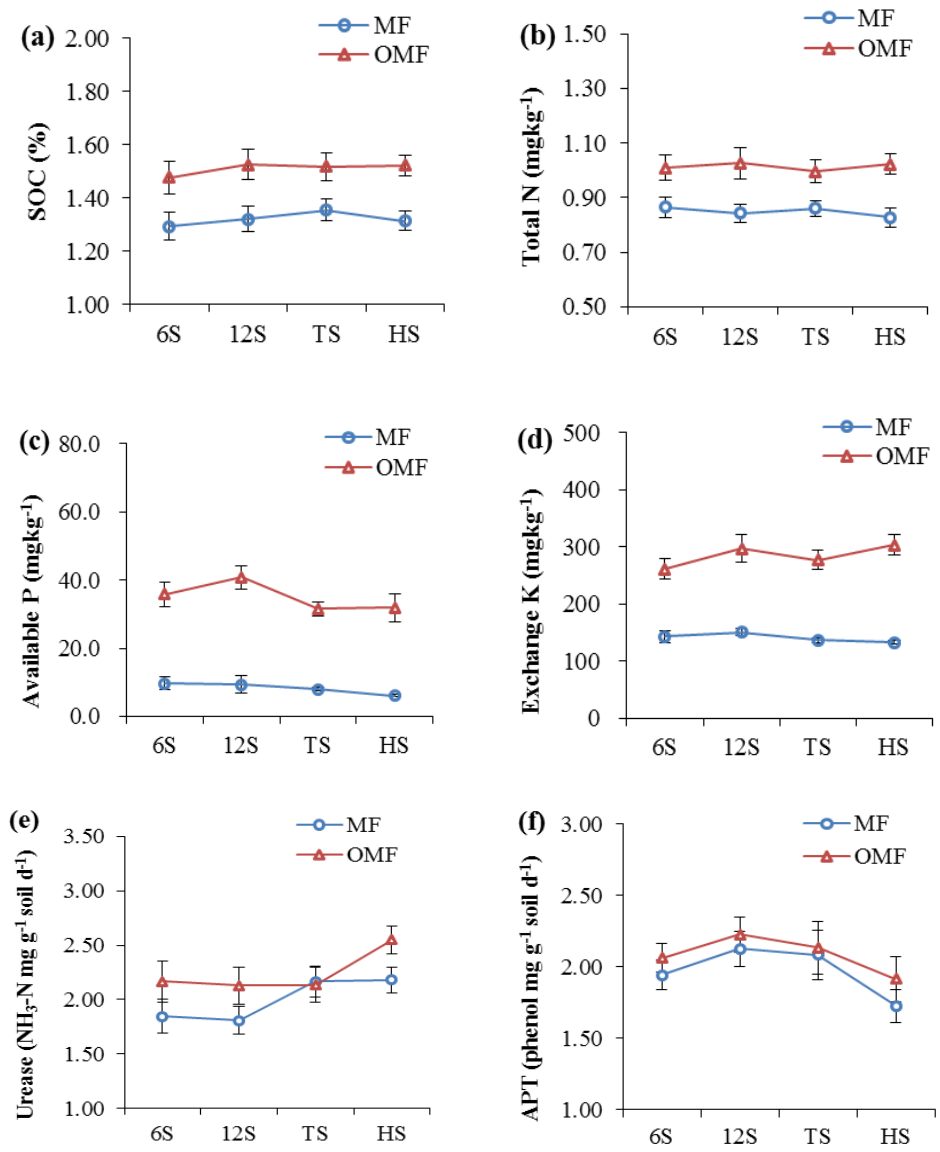

Figure 3. Soil organic carbon (SOC), total N, available P, exchangeable K, urease and alkaline phosphomonoesterase (APT) activity in mineral fertilizer treatments (MF) and the combination of organic and mineral fertilizer treatments (OMF). 6S: six-leaf stage (35 days from seeding); 12S: twelve-leaf stage (53 days from seeding); TS: tasseling stage (66 days from seeding), and HS: harvest stage (118 days from seeding). The data are mean values $\pm \mathrm{SE}$ for the four years $(\mathrm{n}=16)$, except the data of total $\mathrm{N}$ without $2011(\mathrm{n}=12)$. 
The soil urease activity was significantly higher in the OMF treatments than in the MF treatments in the $6 \mathrm{~S}(17 \%, P<0.05)$ and HS $(18 \%, P<0.001)$ over the four years (Figure 3 ). The soil urease activity with OMF was higher in the HS than in the 6S $(P<0.05)$. The soil urease activity with MF was higher in the TS than in the $6 \mathrm{~S}$ and $12 \mathrm{~S}(P<$ $0.05)$. The soil alkaline phosphatase activity was higher in the OMF treatments than in the MF treatments in the $6 \mathrm{~S}(3 \%, P=0.052)$ and HS $(11 \%$, $P<0.05$ ) over the four years (Figure 3 ). The soil alkaline phosphatase activity of both the MF and OMF treatments was higher in the $12 \mathrm{~S}$ than in the HS $(P<0.05)$.

\subsection{Dynamics of maize growth and nutrient absorption}

The results showed that the shoot biomass $(\mathrm{F}=$ 4.933, $P=0.034)$, root biomass $(\mathrm{F}=6.985, P=$ $0.013), \operatorname{root} \mathrm{N}(\mathrm{F}=17.458, P<0.001), \operatorname{root} \mathrm{P}(\mathrm{F}=$ 5.940, $P=0.021)$, shoot $\mathrm{K}(\mathrm{F}=24.053, P<0.001)$ and root $\mathrm{K}(\mathrm{F}=42.231, P<0.001)$ were higher in the OMF treatments than those of the MF treatments over the four years (Figure 4). Furthermore, the biomass and nutrient uptake changes of maize shoots and roots at different growth stages were analysed with the average data over the four years (Figure 5). The shoot biomass was higher in the OMF treatments than in the MF treatments in the $6 \mathrm{~S}(20 \%, P<0.01), 12 \mathrm{~S}(20 \%, P<0.001)$ and TS $(14 \%, P<0.01)$. Compared with the MF treatment, the OMF treatment significantly increased the root biomass in the $6 \mathrm{~S}(24 \%, P<0.05), 12 \mathrm{~S}(23 \%$, $P<0.01)$ and TS $(16 \%, P<0.01)$, respectively.
The shoot $\mathrm{N}$ contents were higher with OMF than with MF in the $6 \mathrm{~S}(28 \%, P<0.01), 12 \mathrm{~S}(12 \%, P<$ $0.001)$ and HS $(18 \%, P<0.01)$, respectively. Root $\mathrm{N}$ was higher in the OMF treatments than in the MF treatments in the $6 \mathrm{~S}(43 \%, P<0.001), 12 \mathrm{~S}$ $(27 \%, P<0.01)$, TS $(16 \%, P<0.01)$ and HS $(17$ $\%, P<0.05)$, respectively. Additionally, shoot $\mathrm{N}$ increased during the whole growing season in the OMF treatments, but it only increased from the $6 \mathrm{~S}$ to the TS in the MF treatments. This result indicated that OMF has a longer N supply capability than MF during maize growth. The shoot $\mathrm{P}$ contents were higher in the OMF treatments than in the MF treatments in the $6 \mathrm{~S}(44 \%, P<0.05), 12 \mathrm{~S}(42 \%$, $P<0.001)$, TS $(22 \%, P<0.01)$ and HS $(23 \%, P$ $<0.001)$, respectively. Shoot $\mathrm{P}$ reached the highest content in the TS $(P<0.05)$. Compared with the MF treatment, the OMF treatment significantly increased the root $\mathrm{P}$ contents in the $6 \mathrm{~S}(55 \%), 12 \mathrm{~S}$ (48\%), TS (31\%) and HS (36\%) at $P<0.001$, respectively. The shoot $\mathrm{K}$ contents were higher in the OMF treatments than in the MF treatments in the 6S (53\%, $P<0.0001), 12 \mathrm{~S}(28 \%, P<0.001)$, TS $(27 \%, P<0.001)$ and HS $(25 \%, P<0.001)$, respectively. The shoot $\mathrm{K}$ contents with OMF were higher in the HS than in the TS $(P<0.05)$, while this phenomenon was not observed with MF. Compared with the MF treatment, the OMF treatment significantly increased the root $\mathrm{K}$ contents in the 6S (51\%), 12S (32\%), TS (31\%) and HS (25\%), respectively $(P<0.001)$. The root $\mathrm{K}$ contents with both OMF and MF was higher in the HS than in the $6 \mathrm{~S}$ and $12 \mathrm{~S}(P<0.05)$, while there was no significant difference between the TS and HS. 

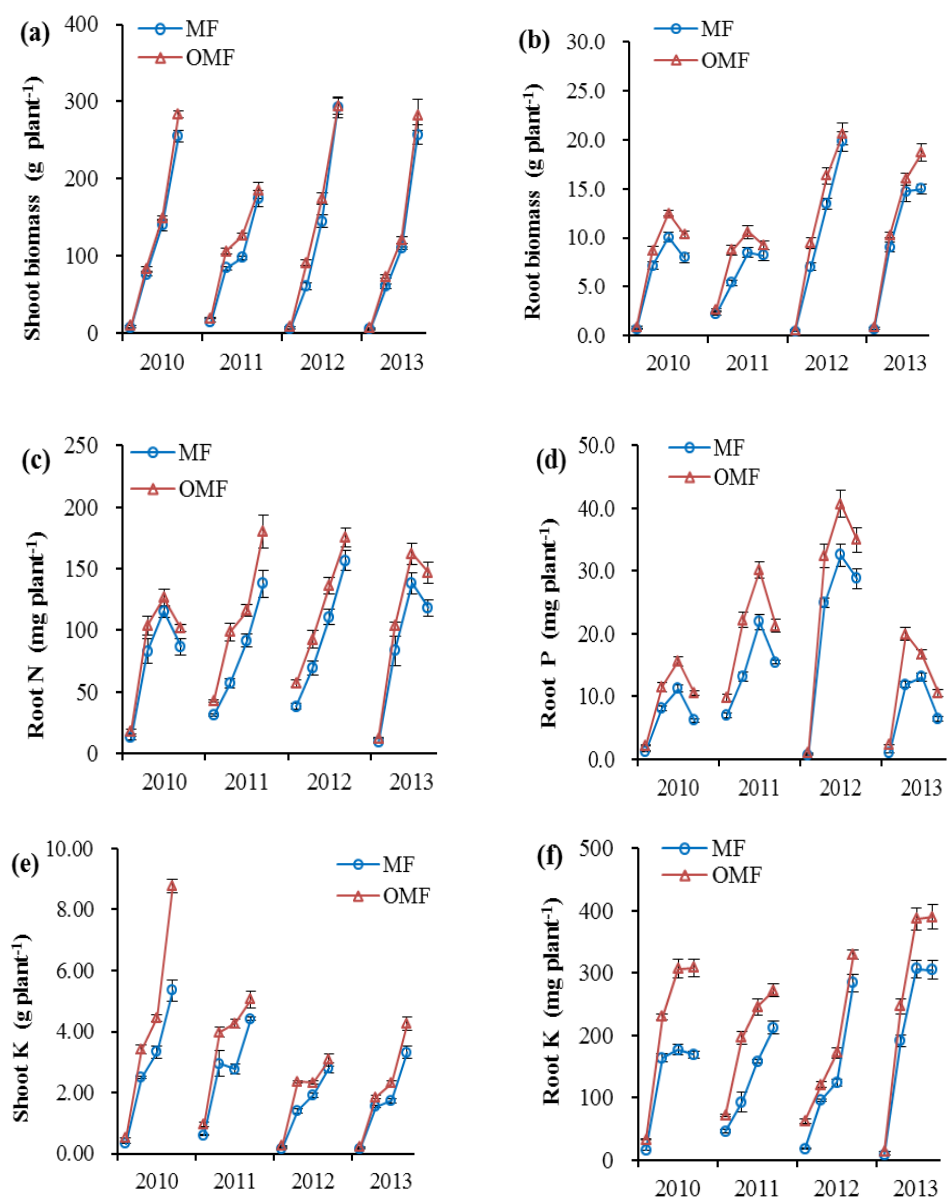

Figure 4. Shoot biomass, root biomass, root $\mathrm{N}$, root $\mathrm{P}$, shoot $\mathrm{K}$ and root $\mathrm{K}$ in the mineral fertilizer treatments (MF) and the treatments with organic fertilizer combined with smaller amounts of mineral fertilizer (OMF). The data are the mean values $\pm \mathrm{SE}(\mathrm{n}=4)$. 

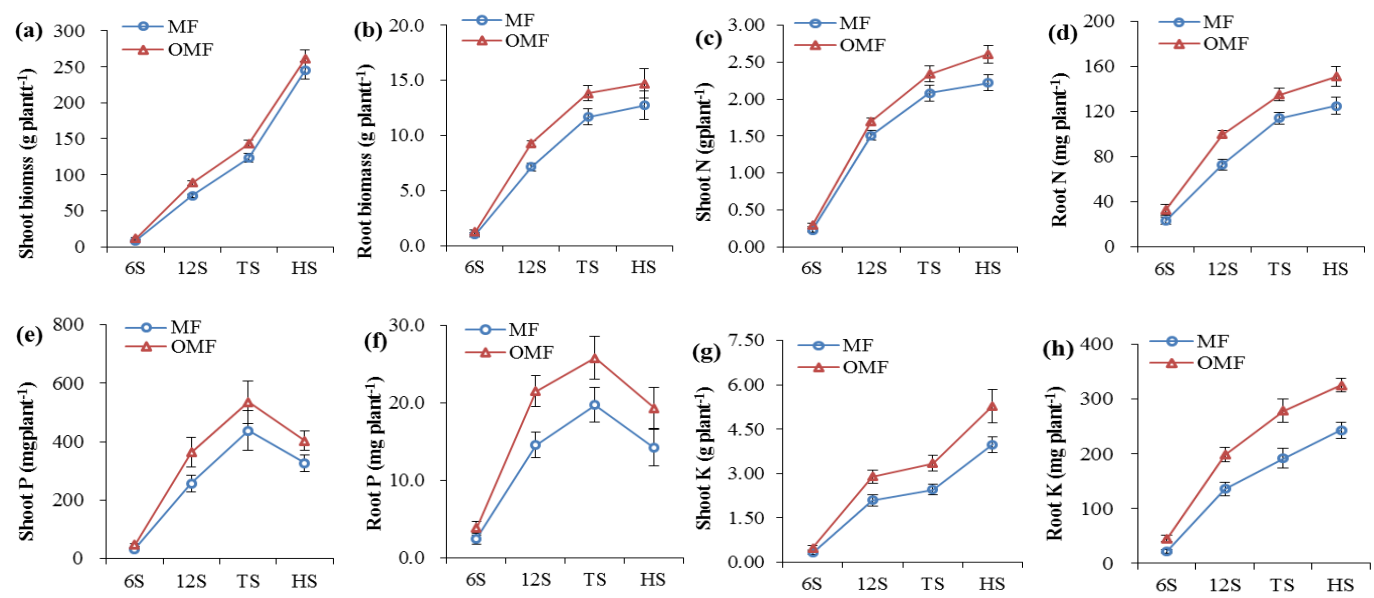

Figure 5. The dynamics of maize biomass and nutrients in mineral fertilizer treatments (MF) and the combination of organic and mineral fertilizer treatments (OMF). 6S: six-leaf stage (35 days from seeding); 12S: twelve-leaf stage (53 days from seeding); TS: tasseling stage (66 days from seeding), and HS: harvest stage (118 days from seeding). The data are the mean values \pm SE for four years $(n=16)$.

\subsection{Environmental impacts}

When expressed per unit of production, the two impacts related to the management of resources were significantly affected by the system (Tables 1 and 2). The total global warming potential of the OMF system was reduced by $79.66 \%$ compared with that of the MF system (Table 1). The $\mathrm{CO}_{2}$ emissions were approximately $80 \%$ and $70 \%$ of the contribution to the global warming potential for the MF and the OMF systems, respectively, while almost $20 \%$ and $10 \%$ were related to direct emissions of $\mathrm{N}_{2} \mathrm{O}$. The total acidification potential that was mainly caused by $\mathrm{NH}_{3}$ volatilization was lower $(60.22 \%)$ in the OMF system than in the MF system. The aquatic eutrophication potential, expressed as $\mathrm{kg}$ per $\mathrm{PO}_{4}$-equivalent, represented the contribution to river and lake ecosystems. In this study, the aquatic eutrophication potential of summer maize production systems was dominated by $\mathrm{NH}_{3}$ volatilization (Table 1). In the OMF system, the total aquatic eutrophication potential was reduced by $60.68 \%$. The soil eco-toxicity potential of the OMF system (which was dominated by $\mathrm{Cu}$ and $\mathrm{Zn}$ ) was increased by $138.57 \%$ compared with the MF system (Table 1). 
Table 1. Pollutant emissions potentials and soil eco-toxicity of a functional plant production unit in the mineral fertilizer treatments (MF) and the combination of organic and mineral fertilizer treatments (OMF) during this four-year experiment

\begin{tabular}{|c|c|c|c|c|c|}
\hline $\begin{array}{l}\text { Emissions } \\
\text { inventory }\end{array}$ & MF & OMF & $\begin{array}{l}\text { Characterization } \\
\text { values }\end{array}$ & MF & OMF \\
\hline & & & $\mathrm{CO}_{2}$-equivalent & \multicolumn{2}{|c|}{ Global warming potentials } \\
\hline $\mathrm{CO}_{2}$ & 215.6327 & 39.129 & 1 & 215.6327 & 39.1289 \\
\hline $\mathrm{CO}$ & 0.0956 & 0.0171 & 2 & 0.1912 & 0.0341 \\
\hline $\mathrm{CH}_{4}$ & 0.0053 & 0.4747 & 21 & 0.1105 & 9.9677 \\
\hline \multirow[t]{3}{*}{$\mathrm{N}_{2} \mathrm{O}$} & 0.1611 & 0.0160 & 310 & 49.9410 & 4.9460 \\
\hline & & & Total & 265.8753 & 54.0766 \\
\hline & & & $\mathrm{PO}_{4}$-equivalent & \multicolumn{2}{|c|}{ Aquatic eutrophication potential } \\
\hline $\mathrm{NH}_{4}$ & 0.3926 & 0.1031 & 0.33 & 0.1296 & 0.0340 \\
\hline $\mathrm{NH}_{3}$ & 2.0208 & 0.8510 & 0.33 & 0.6669 & 0.2808 \\
\hline \multirow[t]{3}{*}{ COD } & 1.6678 & 0.5779 & 0.022 & 0.0367 & 0.0127 \\
\hline & & & Total & 0.8331 & 0.3276 \\
\hline & & & SOx-equivalent & \multicolumn{2}{|c|}{ Acidification potentials } \\
\hline $\mathrm{SO}_{\mathrm{X}}$ & 0.6788 & 0.0603 & 1 & 0.6788 & 0.0603 \\
\hline $\mathrm{NH}_{3}$ & 2.0208 & 0.8510 & 1.88 & 3.7991 & 1.5999 \\
\hline \multirow[t]{3}{*}{$\mathrm{NO}_{\mathrm{X}}$} & 0.7778 & 0.4822 & 0.7 & 0.5444 & 0.3375 \\
\hline & & & Total & 5.0223 & 1.9977 \\
\hline & & & 1,4-DCB-equivalent & \multicolumn{2}{|l|}{ soil eco-toxicity } \\
\hline $\mathrm{Cu}$ & 0.0191 & 0.0360 & 14 & 0.2673 & 0.5043 \\
\hline $\mathrm{Zn}$ & 0.0291 & 0.0803 & 25 & 0.7264 & 2.0079 \\
\hline $\mathrm{Cd}$ & 0.0003 & 0.0008 & 170 & 0.0570 & 0.1362 \\
\hline \multirow[t]{2}{*}{$\mathrm{Pb}$} & 0.0023 & 0.0011 & 33 & 0.0747 & 0.0364 \\
\hline & & & Total & 1.1254 & 2.6847 \\
\hline
\end{tabular}

The values of the $\mathrm{CO}_{2}$-equivalent, $\mathrm{SO}_{\mathrm{x}}$-equivalent, $\mathrm{PO}_{4}$-equivalent and 1, 4-DCB-equivalent are according with Liang et al. (2009). All values are in $\mathrm{kg}$ per ton of grain

The world per-capita environmental impact potentials in 2000 were used as normalization values (Table 2). The energy demand was $37.5 \%$ lower in the OMF system than in the MF system. The results showed that aquatic eutrophication and soil eco-toxicity were two major environmental impacts connected to the production of $1 \mathrm{t}$ of summer maize (Table 2). For summer maize production, the potential of aquatic eutrophication decreased from 0.4431 in the MF system to 0.2145 in the OMF system. These values indicated that the aggregate environmental impact of summer maize per ton in the MF system was $44 \%$ of that of the world per-capita aggregate environmental impacts, whereas it was only $21 \%$ in the OMF system. By contrast, the soil eco-toxicity potential increased from 0.1842 in the MF system to 0.4405 in the OMF system. Although the OMF system showed a higher soil eco-toxicity potential, all of the environmental impact potentials in the OMF system were reduced by $6.86 \%$ compared with those of the MF system. Each normalized indicator value was multiplied by a weighting factor, which represented the potential 
of an impact category to harm resources and natural ecosystems. The aggregate environmental index for maize production decreased from 0.0880 in the MF system to 0.0730 in the OMF system, which indi- cated that the harmful effect of maize production in the OMF system was $17 \%$ lower than that in the MF system (Table 2).

Table 2. Environmental indices of a functional plant production unit in the mineral fertilizer treatments (MF) and the combination of organic and mineral fertilizer treatments (OMF)

\begin{tabular}{|c|c|c|c|c|c|c|c|}
\hline \multirow{2}{*}{$\begin{array}{l}\text { Environmental impact } \\
\text { category (2010-2013) }\end{array}$} & \multirow{2}{*}{ Unit } & \multirow{2}{*}{$\begin{array}{l}\text { Reference } \\
\text { value }\end{array}$} & \multicolumn{2}{|c|}{$\begin{array}{l}\text { Normalization } \\
\text { values }\end{array}$} & \multirow{2}{*}{ Weight } & \multicolumn{2}{|c|}{$\begin{array}{l}\text { Environmental } \\
\text { indices }\end{array}$} \\
\hline & & & MF & OMF & & MF & OMF \\
\hline Energy depletion & $\mathrm{MJ} / \mathrm{t}$ & $2,590,457$ & 0.0008 & 0.0005 & 0.15 & 0.0001 & 0.0001 \\
\hline Global warming & $\mathrm{kg} \mathrm{CO}_{2}-\mathrm{q} / \mathrm{t}$ & 6869 & 0.0387 & 0.0087 & 0.12 & 0.0046 & 0.0010 \\
\hline Aquatic eutrophication & $\mathrm{kg} \mathrm{PO}_{4}$-eq/t & 1.88 & 0.4431 & 0.2145 & 0.12 & 0.0532 & 0.0257 \\
\hline Acidification & $\mathrm{kg} \mathrm{SO}_{2}$-eq/t & 52.26 & 0.0961 & 0.0465 & 0.14 & 0.0135 & 0.0065 \\
\hline \multirow[t]{2}{*}{ Soil eco-toxicity } & kg1,4-DCB-eq/t & 6.11 & 0.1842 & 0.4405 & 0.09 & 0.0166 & 0.0396 \\
\hline & & & & & Total & 0.0880 & 0.0730 \\
\hline
\end{tabular}

Values, which are the respective indicator values per person in the world, were calculated by dividing the indicator values per ton of grain by reference values and weighting. The reference value and weight value are in accordance with Liang et al. (2009).

\section{Discussion}

\subsection{Combination of organic and mineral fertilizers increases maize yield}

Greater maize yield responses were demonstrated for combined organic and mineral fertilizers compared to either resource alone in the exist literature (Chivenge et al., 2011; Zhang et al., 2017). In the present study, higher summer maize yields were observed in the OMF treatments compared to the MF treatments. The critical period for setting grains in maize is from jointing (stem elongation) to flowering (Subedi and Ma, 2009). In the present study, the maize root and shoot biomasses were significantly improved with the application of OMF from the $6 \mathrm{~S}$ to the TS. Additionally, the PCA analysis results showed that the maize yield had a stronger cor- relation with the soil $\mathrm{P}(R=0.350, P<0.05)$, shoot $\mathrm{N}$ $(R=0.655, P<0.01)$, shoot $\mathrm{P}(R=0.527, P<0.01)$ and root $\mathrm{P}(R=0.579, P<0.01)$ at the TS stage (Figure 6). The maize yield also had a stronger correlation with urease activity $(R=0.771, P<0.01)$, alkaline phosphatase activity $(R=0.718, P<0.01)$, shoot $\mathrm{P}(R=0.748, P$ $<0.01)$ and $\operatorname{root} \mathrm{P}(R=0.560, P<0.01)$ at the HS stage. Consequently, the higher yield with OMF was possibly attributed to an increase in soil $\mathrm{P}$ availability, $\mathrm{P}$ and $\mathrm{N}$ uptake by maize at the TS stage, as well as the increase of $\mathrm{P}$ uptakes, urease activity and alkaline phosphatase activity at the HS stage. An equal temporal stability of summer maize yield was shown in the OMF treatments compared with the MF treatments. This result indicated that the combination of mineral and organic fertilizers can provide the same temporal stability of maize yield compared to mineral fertilizers. 


\subsection{Combination of organic and mineral fertilizer improves soil enzymes and nutrients}

A previous study demonstrated that continuous application of the organic fertilizers combined with mineral fertilizers significantly increased the soil organic carbon and microbial biomass (Kaur et al., 2008). The SOC was increased by the OMF treatments compared with the MF treatments. The possible explanation of increased soil organic carbon under the OMF treatments may include (1) the observation that organic fertilizers in the OMF treatments contain significant levels of organic matter, which is a definitive factor in improving the soil structure, aggregate stability and biological activity and (2) the higher levels of carbon fractions from crop residues along with soil microbial activity (Agber, 2012). In North China, maize grows in summer when the annual rainfall peaks and with nitrate leaching down the soil profile through diffusion as well as various bio-pores despite the low mobility of ammonium and $\mathrm{P}$ (Mi et al., 2010). The total soil $\mathrm{N}$ and available $\mathrm{P}$ were significantly higher in treatments with OMF than in those with MF during all growth seasons (Figure 3). This result indicated that the combination of the mineral and organic fertilizers had a higher and steadier $\mathrm{N}$ and $\mathrm{P}$ supply than mineral fertilizers. In a previous study, the positive effect of mineral fertilizers on plant growth, nutrient-use efficiency and productivity disappeared for fertilizer exhaustion, but it occurred again after the second localized application of NP fertilizers (Ma et al., 2013). Their results indicated the importance of persistent nutrient supply for maize growth later in the season. Our results indicated that OMF had a better nutrient supply advantage than MF in both the early and later maize growing seasons. The decrease in the soil available $\mathrm{P}$ in the TS and HS in the OMF or MF treatments was possibly due to the build-up of $\mathrm{P}$ by maize shoot as demonstrated by our results (Figure 5). Additionally, this decrease in soil available $\mathrm{P}$ in the later growing season may also be caused by $\mathrm{P}$ fixation in the soil. The soil and plant $\mathrm{K}$ levels maintained at sufficient levels were essential to achieve maximum crop productivity (Pettigrew, W. T., 2008). In this study, OMF increased the soil $\mathrm{K}$ compared to the MF, indicating that the OMF possibly increased the maize yield by supplying sufficient soil $\mathrm{K}$.

In maize fields, long-term application of mineral fertilizers decreased urease and phosphatase activities as well as dehydrogenase activity, while soil enzyme activities can be related to the availability of nutrients in soil (He et al., 2010). In the present study, OMF increased the urease and alkaline phosphatase activities compared with MF. The alkaline phosphatase activity was higher in the $12 \mathrm{~S}$ than in the TS in the OMF system. Alkaline phosphatase does not have a plant origin and is produced by bacteria, fungi and earthworms (George et al, 2002). Therefore, the change in the alkaline phosphatase activity is possibly attributed to the distinct soil organism compositions that are transformed from the vegetative growth stage (12S) to the reproductive growth stage (TS). This result was consistent with the change in the soil $\mathrm{P}$ in the OMF treatments, indicating that OMF possibly supplies sufficient $\mathrm{P}$ by increasing the alkaline phosphatase activity.

\subsection{Combination of organic and mineral fertilizer promotes nutrient uptake}

Organic fertilizer could promote soil nutrient uptake and plant growth by increasing the soil nutrient supply. Given that the formation of the root system keeps pace with the development of shoots (Peng et al. 2010), the positive effect of application of OMF 
was similar on root and shoot growth from the $6 \mathrm{~S}$ to the TS. Maize shoots and roots required tremendous $\mathrm{N}, \mathrm{P}$ and $\mathrm{K}$ from soil for plant nutrient accumulation. Previous studies showed that mineral fertilizer application caused a $\mathrm{NH}_{3}$ volatilization loss and nitrate leaching through diffusion despite the low mobility of ammonium and $\mathrm{P}$ for peak rainfall (Mi et al., 2010), reducing the maize yields. Our results showed that $\mathrm{N}$ and $\mathrm{P}$ uptake by both maize roots and shoots were increased by application of the OMF, especially in the later growth stages. This result was possibly attributed to the OMF enhanced root branching and deeper root growth in maize at the flowering stage which is important for nutrient uptake in subsoil to improve water- and $\mathrm{N}$ use efficiency (Oikeh et al., 1999). The shoot $\mathrm{P}$ reached its peak content value in the TS in both the MF and OMF treatments. This result was similar to the results of $\mathrm{Li}$ et al. who demonstrated that the peak value of $\mathrm{P}$ accumulation occurred after silking with high available nutrients (Li et al., 2010). The shoot and root $\mathrm{K}$ were higher (25-53\%) in the entire growing season in the OMF treatments than in the MF treatments. This result indicated that OMF significantly promotes $\mathrm{K}$ uptake to maintain a more sufficient $\mathrm{K}^{+}$content level for maize growth than sole mineral fertilizers.

\subsection{Relationships between soil and plant parameters under MF and OMF systems}

The principal components analysis results showed that the urease activity and all plant parameters were negatively correlated with principal component (PC1) (59.6\%), whereas the SOC, APT activity and soil nutrients were negatively correlated with PC2 (27.9\%), indicating that a higher contribution to the total variation was induced by nutrient uptake than by soil nutrients (Figure 6). The greater nutrient uptake benefits with OMF were mainly attributed to the direct interactions between the two resources, and temporary immobilization of $\mathrm{N}$ from fertilizers by organic fertilizers can result in improved synchrony between the supply and demand of nutrients (Palm et al., 2001). The maize yield had a significant positive correlation with the shoot and root biomass $(P<0.01)$. Maize biomass had a significantly positive correlation with the $\mathrm{N}, \mathrm{P}$ and $\mathrm{K}$ uptakes by both shoots and roots $(P<$ $0.01)$. Nutrient uptakes were significantly higher with OMF than with MF in the TS and HS. These results indicated that $\mathrm{OMF}$ promotes maize growth and yield formation, which is possibly attributed to the increase in nutrient uptake at the TS and HS stages. The peak P uptake (both root and shoot) was shown at the $12 \mathrm{~S}$ in both the MF and OMF treatments, while there was a significant decrease in the soil available $\mathrm{P}$ in the OMF treatments. The decrease in the soil $\mathrm{P}$ was possibly attributed to the P uptake by maize at the TS. This result indicated that the OMF supply sufficient $P$ for maize growth at the TS and soil $\mathrm{P}$ possibly a limit factor at this stage to determine maize growth in the later growth stage. The SOC was significantly correlated to the soil $\mathrm{N}$, soil $\mathrm{P}$ and soil $\mathrm{K}$ in the $12 \mathrm{~S}$ in the OMF treatments $(P<0.01)$. The soil nutrient availability is an important factor for maize growth at the seedling stage and may directly contribute to the nutrient-use efficiency and plant productivity at a later stage. Further studies are needed to focus on maize nutrient use at later growth stages to elucidate the relationship among nutrient uptake, nutrient efficiency and final grain yield. The urease activity had a positive correlation with soil nutrients and uptake by plants (except the shoot and root $\mathrm{K}$ contents) in the OMF system (Figure 6). This indicated that the OMF possibly increased the soil nutrient availability and promoted their uptake by increasing the urease activity. 


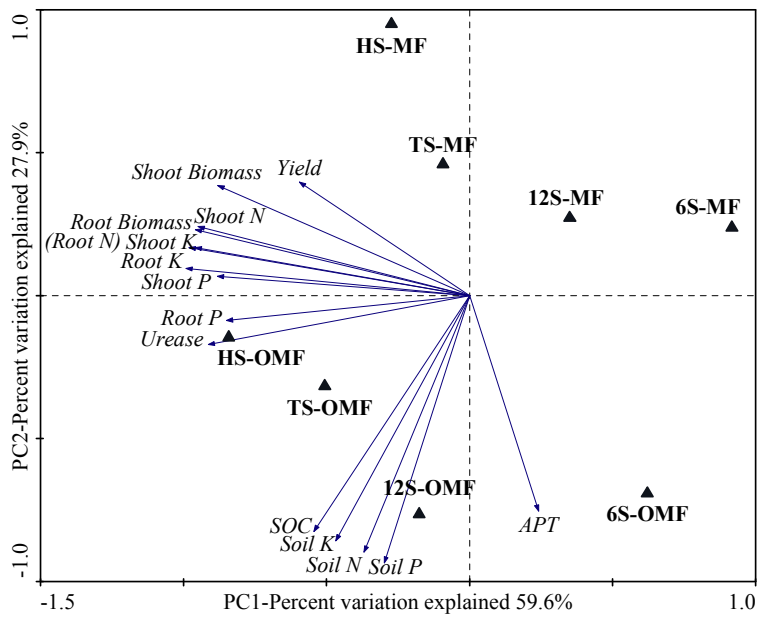

Figure 6. Principal components analysis (PCA) of soil and plant parameters in the MF and OMF systems. PCA illustrated that $\mathrm{PC} 1$ explained $59.6 \%$ of the total variations, which included negative contributions by the urease, nutrient uptakes and maize biomass. PC2 explained $27.9 \%$ of the total variations, which included negative contributions by the SOC, Soil N, Soil P, Soil K and APT (alkaline phosphatase). 6S: six-leaf stage; 12S: twelve-leaf stage; TS: tasseling stage; HS: harvest stage.

\subsection{Environmental impact of both the $M F$ and $O M F$ systems}

The environmental goal of life cycle analysis is to minimize the environmental impacts per unit of product (from raw material extraction to grain production), which can reflect the outlook of the application of the equivalent OMF to the MF system. For LCA studies on arable crop production, the main consumption of fossil fuels and minerals, such as oil, coal, phosphate, potash and lime, are sub-categories of particular importance. The present study suggests that OMF decreased the demand for non-renewable energy resources. The lower energy requirement of the OMF system was mainly due to a reduced input in the $\mathrm{N}$ fertilizers (Deytieux et al., 2012). Deike et $a l$. demonstrated that $\mathrm{N}$ fertilization was ranked first in the energy requirement when all inputs required for crop production were considered (Deike et al., 2008) The Global Warming Potentials of these emissions contributed to the climate change (Table 1). The main reasons for greenhouse gas mitigation in the $\mathrm{OMF}$ system include (i) lower $\mathrm{CO}_{2}$ emissions in organic fertilizer production for reducing fertilizer application and (ii) decreased use of $\mathrm{N}$-fertilizer, which reduces the emissions of ammonia, nitrates and nitrogen oxides and could decrease the emissions of nitrous oxide $\left(\mathrm{N}_{2} \mathrm{O}\right)$ (Nemecek et al., 2008). Acidification is mainly caused by air emissions of sulphur dioxide $\left(\mathrm{SO}_{2}\right.$, share 36\% for EU15), nitrogen oxides (NOx, 33\%) and ammonia $\left(\mathrm{NH}_{3}, 31 \%\right.$; EEA, 2001). In the present study, the acidification potential was dominated by $\mathrm{NH}_{3}$, which was lower with OMF than with MF. This result indicated that applying $\mathrm{N}$ in the organic form could be a useful mitigation option. Depletion of trace elements in soil, together with high usage of 
NPK fertilizers, may decrease the essential trace elements, and copper was deficient in the soil-crop system with chemical fertilization (Kong, 2011). The raw materials of organic fertilizer, such as animal manure, often input some trace elements, which are possibly attributed to the higher $\mathrm{Cu}$ and $\mathrm{Zn}$ content in the OMF. OMF may help to maintain the balance of zinc and copper as micronutrients in arable soils. In the present study, the aggregate environmental index for maize production was $17 \%$ lower in the OMF system than in the MF system. Consequently, the combined application of mineral and organic fertilizers is considered to be a promising solution for reducing the environmental burdens that are related to intensive agricultural management practices.

\section{Conclusions}

The combination of organic and mineral fertilizer could be advantageously utilized for maize cropping, and this practice had higher crop yields and lower environmental risk compared to sole mineral fertilization. Therefore, it was concluded that the combination of organic and mineral fertilizers is a better choice for farmers as reduce the use of chemical fertilizers for sustainable agriculture development. The high and steady yield with OMF (organic and mineral fertilizer) was attributed to increased soil P, N and P uptakes by maize shoot in the TS (tasseling stage) and urease activity with $\mathrm{P}$ uptakes at the HS (harvest stage). The organic fertilizer combined with lower amounts of mineral fertilizer increased maize biomass by increasing the $\mathrm{N}, \mathrm{P}$ and $\mathrm{K}$ uptakes in the $12 \mathrm{~S}$ (twelve-leaf stage) and TS stages. Moreover, OMF demanded less non-renewable energy and alleviated the stress from global warming, acidification and aquatic eutrophication. This research has shed significant light on how the combination of mineral and organic fertilizers promotes soil nutrient supplies to match maize growth in different stages as well as improve the agricultural environment.

\section{Acknowledgements}

This work was financially supported by the National Natural Science Foundation of China (Projects 31570514), Chinese Universities Scientific Fund (Project 2015ZH005) and the Key Projects in the National Science \& Technology Pillar Program during the Twelfth Five-year Plan Period (2013BAD05B03), Innovative Group Grant of the National Science Foundation of China (31421092), and the National Basic Research Program of China (973 Program, 2015CB150405).

\section{References:}

Agber, P.I., Abagyeh, S.O. 2012. Influence of combined application of organic manures and NPK fertilizer on soil physical properties, growth and yield of maize in an alfisol in the Southern Guinea Savanna, Nigeria. Niger. J. Soil Environ. Res. 10, 30-34.

Axmann, H., Sebastianelli, A., Arrillaga, J. 1990. Sample preparation techniques of biological material for isotope analysis. Use of nuclear techniques in studies of soil-plant relationship. Internactional Atomic Energy Agency. Viena, Austria. p. 41-53.

Bremner, J. 1960. Determination of nitrogen in soil by the Kjeldahl method. J. Agric. Sci. 55, 11-33.

Brodt, S., Kendall, A., Mohammadi, Y., Arslan, A., Yuan, J.H., Lee, I.S., Linquist, B. 2014. Life cycle greenhouse gas emissions in California rice production. Field Crops Res. 169, 89-98. 
Carmo, J.B., Filoso, S., Zotelli, L.C., Neto, S., Eraclito, R., Pitombo, L. M., Duarte Neto, P.J., Vargas, V.P., Andrade, C.A., Gava, G.J. 2013. Infield greenhouse gas emissions from sugarcane soils in Brazil: effects from synthetic and organic fertilizer application and crop trash accumulation. GCB Bioenergy. 5, 267-280.

Chivenge, P., Vanlauwe, B., Six, J. 2011. Does the combined application of organic and mineral nutrient sources influence maize productivity? A meta-analysis. Plant Soil. 342, 1-30.

Deike, S., Pallutt, B., Christen, O. 2008. Investigations on the energy efficiency of organic and integrated farming with specific emphasis on pesticide use intensity. Eur. J. Agron. 28, 461-470.

Deytieux, V., Nemecek, T., Knuchel, R.F., Gaillard, G., Munier-Jolain, N.M. 2012. Is integrated weed management efficient for reducing environmental impacts of cropping systems? A case study based on life cycle assessment. Eur. J. Agron. 36, 55-65.

EEA 2001. (European Environment Agency, Copenhagen.) Environmental Signals 2001. EEA regular indicator report.

George, T.S., Gregory, P.J., Wood, M., Read, D., Buresh, R.J. 2002. Phosphatase activity and organic acids in the rhizosphere of potential agroforestry species and maize. Soil Biol.Biochem. 34, 1487 1494.

He, X.L., Li, Y.P., Zhao, L.L. 2010. Dynamics of arbuscular mycorrhizal fungi and glomalin in the rhizosphere of Artemisia ordosica Krasch. in $\mathrm{Mu}$ Us Sandland, China. Soil Biol. Biochem. 42, 1313-1319.

ISO 1998. Environmental ManagementdLife Cycle AssessmentdGoal and Scope Definition and Life Cycle Inventory Analysis. International Standard ISO 14041, ISO, Geneva.
Kaur, T., Brar, B., Dhillon, N. 2008. Soil organic matter dynamics as affected by long-term use of organic and inorganic fertilizers under maize-wheat cropping system. Nutr. Cycl. Agroecosystems. 81, 59-69.

Kong, W. 2011. Risks of heavy metal pollution and product quality in a tomato-radish-greengrocery cropping system under application of commercial organic manure and chemical fertilizers. Plant Nutr. Fertil. Sci. 17, 977-984.

Li, H., Wang, C., Li, X.L., Xiang, D. 2013. Inoculating maize fields with earthworms (Aporrectodea trapezoides) and an arbuscular mycorrhizal fungus (Rhizophagus intraradices) improves mycorrhizal community structure and increases plant nutrient uptake. Biol. Fertil. Soils. 49, 1167-1178.

Li, M., Pei, Z., Zhang, M., Yu, L. 2010. Study on N, P and $\mathrm{K}$ accumulation of maize under high fertilizer level in cold region. J. Maize Sci. 18, 121-125.

Liang, L., Chen, Y.Q., Gao, W.S., Sui, P., Chen, D.D., Zhang, W. 2009. Life cycle environmental impact assessment in winter wheat-summer maize system in north China plain. J. Aro-environ. Sci. 28, 1773-1776.

Ma, Q.H., Zhang, F.S., Rengel, Z., Shen, J.B. 2013. Localized application of $\mathrm{NH}_{4}^{+}-\mathrm{N}$ plus $\mathrm{P}$ at the seedling and later growth stages enhances nutrient uptake and maize yield by inducing lateral root proliferation. Plant Soil. 372, 65-80.

Mapanda, F., Wuta, M., Nyamangara, J., Rees, R.M. 2011. Effects of organic and mineral fertilizer nitrogen on greenhouse gas emissions and plantcaptured carbon under maize cropping in Zimbabwe. Plant Soil. 343, 67-81.

Mi, G., Chen, F., Wu, Q., Lai, N., Yuan, L., Zhang, F. 2010. Ideotype root architecture for efficient nitrogen acquisition by maize in intensive cropping systems. Sci. China Life Sci. 53, 1369-1373. 
Moreno-Cornejo, J., Caballero-Lajarín, A., Faz, Á., Zornoza, R. 2017. Pepper crop residues and chemical fertilizers effect on soil fertility, yield and nutritional status in a crop of Brassica oleracea. J. Soil Sci. Plant Nutr. 17, 648-661.

Murphy, J., Riley, J. 1962. A modified single solution method for the determination of phosphate in natural waters. Anal. Chim. Acta. 27, 31-36.

Nemecek, T., von Richthofen, J.S., Dubois, G., Casta, P., Charles, R., Pahl, H. 2008. Environmental impacts of introducing grain legumes into European crop rotations. Eur. J. Agron. 28, 380-393.

Nie, S.W., Gao, W.S., Chen, Y.Q., Sui, P., Eneji, A.E. 2010. Use of life cycle assessment methodology for determining phytoremediation potentials of maizebased cropping systems in fields with nitrogen fertilizer over-dose. J. Cleaner Prod. 18, 1530-1534.

Oikeh, S.O., Kling, J.G., Horst, W.J., Chude, V.O., Carsky, R.J. 1999. Growth and distribution of maize roots under nitrogen fertilization in plinthite soil. Field Crop Res. 62, 1-13.

Palm, C.A., Gachengo, C.N., Delve, R.J., Cadisch, G., Giller, K.E. 2001. Organic inputs for soil fertility management in tropical agroecosystems: application of an organic resource database. Agric. Ecosyst. Environ. 83, 27-42.

Peng, Y., Niu, J., Peng, Z., Zhang, F., Li, C. 2010. Shoot growth potential drives $\mathrm{N}$ uptake in maize plants and correlates with root growth in the soil. Field Crop Res. 115, 85-93

Pettigrew, W.T. 2008. Potassium influences on yield and quality production for maize, wheat, soybean and cotton. Physiol. Plant. 133, 670-681.

Sanchez, D.F., Pastor, A., Rossing, W.A.H., Kropff, M.J., Lantinga, E.A. 2016. Decomposition, contribution and soil organic matter balances of crop residues and vermicompost in maize-based cropping systems in southwest Mexico. J. Soil Sci. Plant Nutr. 16, 801-817.
Scotti, R., Bonanomi, G., Scelza, R., Zoina, A., Rao, M.A. 2015. Organic amendments as sustainable tool to recovery fertility in intensive agricultural systems. J. Soil Sci. Plant Nutr. 15, 333-352.

Shen, J.B., Cui, Z.L., Miao, Y.X., Mi, G.H., Zhang, H.Y., Fan, M.S., Zhang, C.C., Jiang, R.F., Zhang, W.F., Li, H.G., Chen, X.P., Li, X.L., Zhang, F.S. 2013. Transforming agriculture in China: from solely high yield to both high yield and high resource use efficiency. Global Food Secur. 2, 1-8.

Shitan, B. 2000. Soil and agricultural chemistry analysis. Chinese Agriculture Press.

Subedi, K.D., Ma, B.L. 2009. Assessment of some major yield limiting factors on maize production in a humid temperate environment. Field Crop Res. 110, 21-26.

Wang, C., Li, X.L., Gong, T.T., Zhang, H.Y. 2014. Life cycle assessment of wheat-maize rotation system emphasizing high crop yield and high resource use efficiency in Quzhou County. J. Cleaner Prod. 68, 56-63.

Xie, J., Hu, L.L., Tang, J.J., Wu, X., Li, N., Yuan, Y.G., Yang, H.S., Zhang, J.E., Luo, S.M., Chen, X. 2011. Ecological mechanisms underlying the sustainability of the agricultural heritage ricefish coculture system. Proc. Natl. Acad. Sci. 108, 1381-1387.

Xue, L., Mupondwa, E., Panigrahi, S., Tabil, L., Adapa, P. 2012. Life cycle assessment of densified wheat straw pellets in the Canadian Prairies. Int. J. Life Cycle Assess. 17, 420-431.

Yang, Z.C., Zhao, N., Huang, F., Lv, Y. 2015. Longterm effects of different organic and inorganic fertilizer treatments on soil organic carbon sequestration and crop yields on the North China Plain. Soil Tillage Res. 146, 47-52. 
Yang, Z.C., Zhao, N., Huang, F., Lv, Y. 2015. Longterm effects of different organic and inorganic fertilizer treatments on soil organic carbon sequestration and crop yields on the North China Plain. Soil Tillage Res. 146, 47-52.
Zhang, H., Yu, X., Jin, Z., Zheng, W., Zhai, B., Li, Z. 2017. Improving grain yield and water use efficiency of winter wheat through a combination of manure and chemical nitrogen fertilizer on the Loess plateau, China. J. Soil Sci. Plant Nutr. 17, 461-474. 